Katarina Zavišin*

УДК 371.3:81'243(497.11)

Univerzitet u Beogradu

ДОИ https://doi.org/10.18485/analiff.2017.29.2.5

Filološki fakultet

\title{
ZAVRŠNI ISPIT ZA STRANI JEZIK NA KRAJU SREDNJOŠKOLSKOG OBRAZOVANJA U DVOJEZIČNOJ (CLIL) NASTAVI: PREDLOG MODELA ZA OBRAZOVNI SISTEM REPUBLIKE SRBIJE
}

Od 2000. godine Ministarstvo obrazovanja Srbije započinje niz projekata sa ciljem osavremenjavanja opšteg obrazovnog sistema u zemlji kao što je učenje najmanje dva strana jezika tokom dvanaest godina osnovnog i srednjeg obrazovanja i tri ili više jezika u okviru izbornih predmeta. Sastavni deo ovih prjekata čini i uvođenje dvojezične nastave na stranom jeziku u osnovnoj i srednjoj školi (Filipović et al., 2007:234). Rešenjem Ministarstva prosvete i sporta u Trećoj beogradskoj gimnaziji se od školske 2004/2005. godine uvodi dvojezična nastava na francuskom, odnosno italijanskom jeziku po principu CLIL metode (Vučo, 2006:42). Nakon toga, 2015. godine ministar prosvete donosi „Pravilnik o bližim uslovima za ostvarivanje dvojezične nastave " ${ }^{\text {"1 }}$ kojim, međutim, nisu određeni u potpunosti svi elementi dvojezične nastave na stranom jeziku. U ovom radu bavimo se jednim od segmenata koji nedostaju u zakonskoj regulativi obrazovnog sistema. Reč je o završnom ispitu na srednjoškolskom nivou sa posebnim osvrtom na strani jezik (italijanski jezik kao posredni). Stoga je u radu ukratko prikazana organizacija CLIL nastave na srednjoškolskom nivou u obrazovnim sistemima pojedinih evropskih zemalja sa posebnim osvrtom na italijanski sistem, kao i struktura završnog (maturskog) ispita u cilju predočavanja pojedinih modela koji bi se mogli primeniti u Republici Srbiji. Pored toga, u radu je prikazan primer testa za italijanski jezik koji bi po svojoj strukturi i sadržaju mogao biti smernica za proveru jezičkih kompetencija stranog jezika u CLIL nastavi u okviru završnog (maturskog) ispita.

Ključne reči: dvojezična nastava, strani jezik, CLIL metoda, srednjoškolsko obrazovanje, maturski ispit, Treća beogradska gimnazija, italijansko-srpska sekcija, obrazovni sistem Republike Srbije

\footnotetext{
* katarina.zavisin@gmail.com

1 Službeni glasnik RS“, br. 105/2015, 50/2016.
} 


\section{Uvod}

Pod pojmom dvojezične nastave $u$ ovom radu podrazumevamo upotrebu stranog jezika kao posrednog jezika u nastavi nejezičkih predmeta. Ovakav kontetst nastave poznat je pod nazivom "Integrisano učenje jezika i sadržaja" (engl. Content and Language Integrated Learning), te se u naučnoj literatura uobičajeno koristi skraćenica CLIL.

Potrebno je istaći da CLIL nastava ne predstavlja puko ,prevođenje“ nejezičkog sadržaja sa maternjeg jezika na strani, već je reč o metodi u kojoj strani jezik i predmetni sadržaj imaju podjednaku važnost i predstavljaju dvostruki cilj nastave. Stoga je za razumevanje koncepta CLIL nastave neophodno imati u vidu ovakav integrisan pristup u nastavi (Coyle et al. 2010: 27).

S tim u vezi, brojna istraživanja ukazuju na nesumnjivu dobit za učenike, kako u pogledu usvajanja stranog jezika, a posebno razvijanja akademskih kompetencija na stranom jeziku, tako i u pogledu savladavanja sadržaja nejezičkog predmeta (Danesi, 1999; Cummins \& Swain 1986; Titone, 1972). Naime, u tradicionalnoj nastavi stranog jezika učenik pre svega razvija osnovne međuljudske komunikativne sposobnosti (engl. $\mathrm{Ba}$ sic Interpersonal Communicative Skills - BICS). S obzirom da je u CLIL nastavi strani jezik formalan i da sadrži apstraktne pojmove, te je kao takav kognitivno zahtevan, učenik razvija i kognitivnu akademsku jezičku sposobnost (engl. Cognitive Academic Language Proficiency - CALP) na stranom jeziku (Cummins \& Swain, 1986). Na osnovu ovih odlika i rezultata došlo je do uvođenja dvojezične nastave na stranom jeziku u obrazovne sisteme brojnih zemalja širom sveta.

U skladu sa predmetom našeg rada istaći ćemo primere bilingvalne nastave u kojima je, pored maternjeg, zastupljen i strani jezik kao posredni jezik u nastavi nejezičkih predmeta, kao i strukturu završnog (maturskog) ispita na kraju srednjoškolskog obrazovnog ciklusa.

\section{CLIL nastava na srednjoškolskom nivou obrazovanja u Evropi}

CLIL nastava počela je se primenjuje u evropskim zemljama 1995. godine nakon donošenja rezolucije Evropske Komisije i zvaničnog dokumenta za obrazovanje i usavršavanje nastave u kojima se ističe značaj ino-

vativnih ideja u obrazovanju u cilju omogućavanja građanima Evropske 
Unije da steknu kompetencije na tri strana (evropska) jezika. S tim u vezi, Evropska Komisija preporučuje uvođenje stranog jezika kao posrednog jezika u nastavi nejezičkih predmeta u srednjim školama, po ugledu na Evropske škole. Stoga je EU u periodu od 2000. do 2006. pokrenula niz programa sa ciljem uvođenja CLIL nastave u srednjoškolsko obrazovanje, podsticanja interdisciplinarnog pristupa u nastavi, kao i usavršavanja kompetencija nastavnika nejezičkih predmeta u vezi sa CLIL metodom i znanjem stranih jezika (Eurydice, 2006: 8, 9).

Značajan primer za bilingvalni program na srednjoškolskom nivou predstavljaju Evropske škole (engl. European schools) ${ }^{2}$ čiji su primarni ciljevi negovanje višejezičnosti i multikutulturalnosti u okviru Evropske unije. Stoga ih mnogi autori koji proučavaju CLIL i dvojezičnu nastavu, poput Bejkera (Baker u Auer \&Wei, 2007:132), ubrajaju u dobre primere prakse bilingvalne nastave.

Naime, primarni cilj Evropskih škola (Beardsmore, 1993: 121) predstavlja, sa jedne strane, negovanje maternjeg jezika učenika i kulturnog identita i, sa druge strane, razvijanje evropskog identiteta posredstvom CLIL modela, tj. praćenje nastave na najmanje dva jezika. Pored toga, $u$ školskom kurikulumu zastupljen je i treći strani jezik, dok je istovremeno omogućeno učenicima da uče i četvrti strani jezik.

Izbor predmeta u kojima se nastava odvija na stranom jeziku razlikuje se od zemlje do zemlje, često i od regije do regije unutar jedne zemlje, ali i od škole do škole (kao što je slučaj sa Holandijom). U najvećem broju zemalja u Evropi moguće je predavati bilo koji predmet na stranom jeziku osim nastave maternjeg jezika i književnosti što je posebno istaknuto $u$ obrazovnim sistemima pojedinih zemalja kao što su Mađarska, Poljska i Rumunija (Eurydice, 2006: 24 ).

Kada je reč o testiranju u dvojezičnim školama ono najčešće podrazumeva proveru znanja CLIL predmeta na stranom jeziku, ali se ističe da je fokus krtiterijuma za ocenjivanje pre svega na sadržaju nejezičkog predmeta. U pojedinim zemljama (Mađarska, Irska i Austrija) učenici mogu da izaberu da li će prilikom testiranja, odnosno ocenjivanja koristiti strani jezik ili maternji (Eurydice,2006: 29).

2 https://www.eursc.eu/en/European-Schools/mission 


\section{Maturski ispit u CLIL kontekstu: evropska iskustva}

U ovom poglavlju osvrnućemo se na primere pojedinih bilingvalnih škola koje na osnovu organizacije nastave mogu poslužiti kao smernice za maturski ispit za Treću beogradsku gimnaziju, odnosno za bilingvalni program sa stranim jezikom kao posrednim u obrazovnom sistemu Republike Srbije.

Mađarska je jedna od evropskih zemalja koja neguje dvojezično obrazovanje prema CLIL modelu na regionalnom i/ili manjinskom jeziku počev od pedesetih godina XX veka. S tim u vezi, u Mađarskoj ${ }^{3}$ prilikom upisa u srednju školu u bilingvalno odeljenje (najčešće je reč o engleskom kao poredničkom jeziku) učenici poseduju nivo A2 prema ZERO-u ${ }^{4}$. Cilj koji se postavlja za učenike koji prate nastavu dvojezičnog programa jeste da steknu podjednake kompetencije iz nejezičkih predmeta kao i učenici koji prate ove sadržaje na maternjem jeziku. Pored toga, učenici treba da razviju akademske kompetencije na stranom jeziku te je školskim kurikulumom predviđen veći nedeljni fond časova stranog jezika tokom prve godine gimnazije (12 časova nedeljno). Na završnom ispitu učenici koji su pratili bilingvalni program imaju pravo, ukoliko to žele, da polažu završni ispit (nejezički predmet) na stranom jeziku.

U francuskim srednjim školama (Tardieu, \& Dolitsky, 2012: 4) koje neguju dvojezičnu nastavu, preduslov da učenici polažu na završnom ispitu predmet na stranom jeziku jeste da su prethodno položili ispit iz stranog jezika (nivo B2 prema ZERO-u). Nakon toga, biraju predmet za maturski ispit koji su pratili na stranom jeziku i pristupaju usmenom ispitu. Najčešće učenici na ispitu dobiju nepoznati tekst u vezi sa izabranim predmetom na stranom jeziku, pipremaju se oko trideset minuta za izlaganje, a potom odgovaraju na dodatna pitanja komisije u skladu sa utvrđenom formom ispitivanja. Na svedočanstvu učenika koji je izabrao tzv. CLIL predmet za maturski ispit nalazi se ocena koju je učenik dobio i to prema sledećem kriterijumu: $80 \%$ predstavlja rezultat na maturskom ispitu, dok $20 \%$ čini prosek učenikove ocene tokom školovanja.

3 U radu je opisan primer mađarsko-engleske gimnazije Tončiš Mihalj (mađ.Táncsics Mihály) koja primenjuje CLIL nastavu u svom kurikulum, detaljnije na sajtu: http://archive.ecml.at/mtp2/ensemble/results/Kapitanffy.htm

4 Zajednički Evropski referentni okvir za žive jezike 
U programima tzv. Evropskih škola ističe se da učenici treba da razviju kompetencije na stranom jeziku u cilju praćenja nastave nejezičkih predmeta. S tim u vezi, za završni ispit predviđeno je da učenici izaberu za polaganje predmete na maternjem i stranom jeziku (podjednako zastupljene), dok drugi strani jezik polažu kao poseban predmet ili kao posredni jezik u kontekstu nejezičkog predmeta (Beardsmore, 1993:122).

Sve zemlje na kraju srednjoškolskog ciklusa dvojezičnih škola obezbeđuju učenicima potvrdu da su pratili nastavu na stranom jeziku. S tim u vezi, najčešće je praksa da se bilateralnim sporazumima između pojedinih zemlja obezbedi učenicima prohodnost ka fakultetima, te su tako na primer učenici iz Češke, Poljske, Nemačke, Mađarske i Bugarske oslobođeni testa iz stranog jezika prilikom upisa na fakultete (Eurydice,2006: 29).

\section{Dvojezična (CLIL) nastava u obrazovnom sistema Republike Italije}

U sladu sa propisima koje nalaže Ministarstvo prosvete Republike Italije $\mathrm{e}^{5}$ u Italiji se, počev od školske 2010. godine., uvodi nastava na stranom jeziku na srednjoškolskom nivou prema sledećim modulima: u završnim godinama gimnazija jezičkog smera (ital. Licei Linguistici) i to u trećem, četvrtom i petom razredu, kao i u petom razredu srednjih stručnih škola (ital. Istituti tecnici) i ostalih smerova gimnazija. ${ }^{6}$

Izbor nejezičkih nastavnih predmeta prepušten je obrazovnim institucijama (u skladu sa organizacionim mogućnostima svake škole tj. raspoloživosti nastavnika nejezičkih predmeta i njihovoj stručnosti na stranom jeziku). Škole imaju mogućnosti da obezbede anagažovanje nastavnika stranih jezika, kao i tzv. jezičkih asistenata i drugih stručnjaka iz oblasti CLIL nastave kako bi definisala organizaciju u skladu sa sopstvenim mogućnostima. ${ }^{7}$ Takođe, škole imaju slobodu u izboru stranog odnosno

5 http://www.miur.gov.it/clil http://www.istruzione.it/allegati/2014/Norme Transitorie_CLIL_Licei_Istituti_Tecnici_Lug2014.pdf

6 Italijanski obrazovni sistem podrazumeva petogodišnje trajanje srednjoškolskog obrazovanja tzv. drugi ciklus koji pohađaju učenici uzrasta od 14. do 19. godina. Više o italijanskom obrazovnom sistemu na internet sajtu: http://www.miur.gov.it/ sistema-educativo-di-istruzione-e-formazione

7 Detljije o organizaciji CLIL nastave u obrazovnom sistemu Republike Italije dostupno na internet sajtu Ministarstva prosvete Republike Italije: http://www.miur.gov.it/clil 
stranih jezika kao posrednog jezika u CLIL nastavi. Tako na primer, u gimnazijama jezičkog smera u kojima se podučavaju tri strana jezika (tzv. jezici Evropske unije, a to su najčešće, pored engleskog, francuski, nemački i španski jezik) moguće je uvesti u nastavu sva tri jezika u podučavanju različitih nejezičkih predmeta. Sa druge strane, za stručne škole i ostale tipove gimnazija posredni jezik u nastavi odnosi se pre svega na engleski jezik. Glavni cilj jeste da se CLIL nastavom pokrije više od polovine godišnjeg plana i programa određenog nejezičkog predmeta. ${ }^{8}$

\section{Maturski ispit u italijanskom obrazovnom sistema i CLIL nastava}

Po okončanju srednje škole, na završnom (maturskom) ispitu tzv. "Državnom ispitu drugog ciklusa" (ital. Esame di Stato di secondo ciclo) predmet koji se izučavao na stranom jeziku regularno ulazi u izbor predmeta, poput ostalih koji su učenici pratili na maternjem jeziku. Pisano polaganje nejezičkog predmeta koji su učenici pratili na stranom jeziku obavlja se na maternjem jeziku, dok je za usmeni deo ispita moguće polaganje na stranom jeziku ukoliko je član komisije nastavnik koji je izvodio nastavu na stranom jeziku?

Maturski ispit za srednje škole obuhvata tri predmeta, dok se svaki ispit sastoji iz pismenog i usmenog dela. Prvi ispit odnosi se na nastavni predmet Italijanski jezik i podrazumeva pisanje sastava argumentativnog žanra na jednu od obično četiri ponuđene teme (u vezi sa analizom i tumačenjem književnog teksta, ili u vezi sa istorijsko-političkom, društveno - ekonomskom ili naučnom temom). ${ }^{10}$

Drugi ispit se razlikuje u zavisnosti od tipa tj. smera srednje škole, te tako za klasičnu gimnaziju ovaj ispit podrazumeva prevod teksta sa starogrčkog ili latinskog, za gimnaziju prirodnog smera to može biti matematika ili fizika, dok za gimnazije jezičkog smera Ministarstvo prosvete

8 http://www.istruzione.it/allegati/2014/Norme_Transitorie_CLIL_Licei_Istituti Tecnici Lug2014.pdf

9 http://www.miur.gov.it/web/guest/domande-e-risposte

Detaljnijeinformacije dostupne na sajtu: http://www.istruzione.it/allegati/2014/ Norme Transitorie CLIL_Licei_Istituti_Tecnici_Lug2014.pdf

$10 \mathrm{http}: / / \mathrm{www}$. istruzione.it/esame di stato/index.shtml 
Republike Italije (ital. Ministero dell'Istruzione, università e ricerche) bira jedan od tri strana jezika koji se uče u školi i koji će određene školske godine biti predmet polaganja drugog ispita. U okviru pismenog dela drugog ispita učenici imaju mogućnost da biraju jedan od četiri ponuđena teksta (prvi je najčešće u vezi sa nekom od aktuelnih društveno-političkih tema, drugi se odnosi na društveno-istorijsku temu, treći tekst je odlomak iz nekog književnog dela, dok četvrti tekst obrađuje temu iz oblasti umetnosti). Pismeni deo ispita podrazumeva odgovore na pitanja u vezi sa razumevanjem i analizom teksta, kao i pisanu produkciju u vezi sa temom određenog teksta. Na ovom delu testiranja učenici mogu da koriste jednojezične i dvojezične rečnike. ${ }^{11}$

Usmeni deo maturskog ispita sastoji se iz tri dela: u prvom delu učenik izlaže sadržaj svog maturskog rada (ital. tesina); u drugom delu komisija postavlja pitanja ili traži dodatna objašnjenja u vezi sa maturskim radom, dok u trećem delu komisija izlaže učeniku rezultate pismenog dela ispita, postavlja dodatna objašnjenja i pitanja. Pored toga, od 2015. godine postoji mogućnost da u usmeni deo ispita bude uključen i četvrti deo ispita koji se odnosi na nejezički predmet koji je učenik pratio na stranom jeziku (CLIL) samo ukoliko je član ispitne komisije nastavnik koje je predavao određeni predmet na stranom jeziku. ${ }^{12}$

Treći ispit podrazumeva pismeno i usmeno polaganje predmeta koji je usko stručan za određeni smer škole i obuhvata više predmeta koji su učenici pratili u poslednjoj, petoj godini srednje škole. Izbor i strukturu trećeg ispita određuje komisija za maturski ispit svake škole. U slučaju da je jedan od nastavnih predmeta trećeg ispita ujedno i predmet koji su učenici pratili na stranom jeziku tj. u kontekstu CLIL nastave, prema pravilniku Ministarstva prosvete pismeni deo ispita ne može se odvijati na stranom jeziku, već isključivo na italijanskom jeziku. Međutim, za usmeni deo ispita moguće je tražiti od učenika da se služi i stranim jezikom pod uslovom da je član ispitne komisije nastavnik koji je i predavao dati predmet na stanom jeziku. ${ }^{13}$

\footnotetext{
11 https://www.studenti.it/seconda_prova liceo_linguistico_esame di maturita. $\underline{\mathrm{html}}$

12 https://www.studenti.it/esame-orale-maturita.html

13 http://www.istruzione.it/esame di_stato/faq_sc 2016-17.shtml
} 


\section{Dvojezična nastava u Trećoj beogradskoj gimnaziji: srpsko-italijanska sekcija}

Na osnovu rešenja Ministarstva prosvete i sporta u Trećoj beogradskoj gimnaziji se od školske 2004/2005. godine uvodi dvojezična nastava na francuskom, odnosno italijanskom jeziku. Ovim rešenjem predviđeno je da se dvojezična (CLIL) nastava odvija tokom četiri razreda gimnazije, društveno-jezičkog smera, prema nastavnom planu i programu za gimnazije. Takođe, rešenjem je određeno da se deo nastave na stranom jeziku održava u obimu od najmanje $30 \%$, a najviše $45 \%$ od ukupnog godišnjeg fonda časova (Vučo, 2006:42).

U školskoj 2016/17 $7^{14}$ nastava na italijanskom jeziku izvodi se iz sledećih predmeta: Latinski jezik, Logika, Filozofija, Građansko vaspitanje, Istorija, Fizika, Računarstvo i informatika. U izvođenju dvojezične nastave učestvuje i strana lektorka za italijnski jezik koja predstavlja jedan od oblika podrške Republike Italije. Naime, dvojezična nastava u okviru itajansko-srpske sekcije podrazumeva saradnju profesorki koje izvode nastavu na italijanskom jeziku sa profesorkom italijanskog jezika i lektorkom za italijanski i najčešće se ogleda u sledećim segmentima: pripremi dodatnih didaktičkih materijala i testova, ocenjivanju usmenih i pisanih produkcija učenika, kao i u zajedničkom prisustvu i izvođenju časova na oba jezika.

\section{Maturski ispit za dvojezična odeljenja: Treća beogradska gimnazija}

Godine 2015. ministar prosvete, nauke i tehnološkog razvoja Republike Srbije donosi „Pravilnik o bližim uslovima za ostvarivanje dvojezične nastave $^{\text {"15 }}$ (u daljem tekstu PDN - Pravilnik o dvojezičnoj nastavi) . Pravilnikom se utvrđuju detaljniji uslovi u vezi sa dobijanjem saglasnosti za izvođenje CLIL nastave u osnovnim i srednjim školama, prijemnim ispitom za proveru nivoa stranog jezika učenika, nastavnim kadrom i kompetencija-

14 Neobjavljeni izveštaj o radu bilingvalnih odeljenja u školskoj 2016/17. Autorke izveštaja: Biljana Mijajlović, rukovodilac aktiva za italijanski jezik i Dragana Pavović, rukovodilac aktiva za francuski jezik „Službeni glasnik RS“, br. 105/2015, 50/2016. 
ma na stranom jeziku, kao i praćenjem i vrednovanjem kvaliteta realizacije dvojezične nastave. Međutim, s obzirom da pomenutim pravilnikom nije određen sadržaj maturskog ispita za dvojezična odeljenja, za završni ispit za učenike koji su pratili nastavu u skladu sa CLIL metodom primenjuje se zakon za gimnazije društveno-jezičkog smera (Zakonu o srednjem obrazovanju Republike Srbije ${ }^{16}$ ). Tako, prema Pravilniku o ispitima u Trećoj beogradskoj gimnaziji ${ }^{17}$ maturski ispit podrazumeva dva dela: zajednički i izborni. U okviru zajedničkog dela završnog ispita učenici polažu pismeno srpski jezik i književnost i jedan od sledećih predmeta: strani jezik ili matematiku.

Za maturski ispit iz srpskog jezika učenicima su na raspolaganju četiri teme: prva je vezana za književnost i najčešće podrazumeva analizu nekog romana, druga se odnosi na aktuelnu temu (npr. odnos između tehnološkog razvoja društva i humanosti), treća podrazumeva razmatranje ekološkog problema, dok je četvrta u vezi sa učenikovim planovima za budućnost.

Učenici društveno-jezičkog smera polažu ispit iz stranog jezika. Ispit iz stranog jezika se sastoji iz pismenog prevoda sa italijanskog na srpski jezik uz pomoć dvojezičnih i jednojezičnih rečnika. Učenik bira jedan od četiri teksta različitog žanra: publicistički, naučno-popularni ili književni (jedan odlomak iz starije i jedan iz novije književnosti). Tekstovi su nivoa B2 prema kriterijumima ZERO-a, dužine oko 300 reči. Pravilnikom je definisan opšti kriterijum za ocenjivanje prevoda, te tako nastavnik italijanskog jeziku ocenjuje stepen usvojenosti predviđenih morfosintaksičkih struktura, poznavanje osobenosti jezika sa koga se prevodi, sposobnost prevođenja odgovarajućih reči i izraza na maternji jezik i osposobljenost za korišćenje rečnika.

S obzirom da PDN ne definiše strukturu maturskog ispita za dvojezična odeljenja učenici mogu da izaberu za izradu maturskog rada bilo koji nastavni predmet, uključujući i onaj koji su pratili isključivo na maternjem jeziku. Ukoliko učenik izabere predmet koji nije pratio na stranom jeziku, maturski rad izrađuje na srpskom jeziku. Međutim, učenicima dvojezič-

16 http://www.mpn.gov.rs/wp-content/uploads/2015/08/\%D0\%97\%D0\%B0\%D0\% BA\%D0\%BE\%D0\%BD-\%D0\%BE-\%D1\%81\%D1\%80\%D0\%B5\%D0\%B4\%D 1\%9A \%D0\%B5\%D0\%BC-\%D0\%BE\%D0\%B1\%D1\%80\%D0\%B0\%D0\%B7\% D0\%BE\%D0\%B2\%D0\%B0\%D1\%9A\%D1\%83-\%D0\%B8-\%D0\%B2\%D0\%B0 \%D1\%81\%D0\%BF\%D0\%B8\%D1\%82\%D0\%B0\%D1\%9A\%D1\%83.pdf

17 Pravilnik o ispitima, delovodni broj 01-2808 od 26.12.2013.godine, donet od strane organa upravljanja, odnosno Školskog odbora. 
nog odeljenja preporučuje se da izaberu jedan od predmeta koji su pratili na italijanskom jeziku. Ukoliko učenik izabere predmet koji je pratio na italijanskom jeziku, rad piše u dve verzije, jednu na stranom, a drugu na maternjem jeziku. Rad se brani usmeno na stanom jeziku, služeći se po potrebi i maternjim jezikom. Komisiju za odbranu master rada čini predmetni nastavnik koji vodi nastavu na italijanskom jeziku, drugi predmetni nastavnik i odeljenski statešina (poslednja dva najčešće ne govore italijanski jezik te stoga profesorka italijanskog jezika po potrebi vrši medijaciju u okviru komisije).

U slučaju da učenik izabere predmet Italijanski jezik, rad piše na stranom jeziku, te je i usmena odbrana rada na stranom jeziku. Teme koje su na raspolaganju učenicima obuhvataju prikaz određenih gramatičkih kategorija i ilustracija njihove primene (npr. upotreba prošlih vremena, komparacija prideva i priloga, upotreba konjunktiva i sl.). Tokom izrade maturskog rada učenici imaju mogućnost da se konsultuju sa profesorkom stranog jezika ${ }^{18}$ koja ih upućuje u literatura i pruža neophodne smernice. Na usmenoj odbrani maturskog rada profesorka stranog jezika i strana lektorka čine komisiju i usmeno ispituju kandidate na italijanskom jeziku.

Kada je reč o formalnim aspektima i daljim mogućnostima učenika dvojezičnih odeljenja, 2017. godine potpisan je Memorandum o saradnji (ital. Memorandum d'intesa) ${ }^{19}$ između Italije i Srbije, međutim pomenuti bilateralni sporazum ne podrazumeva nikakve formalne olakšice za učenike pri eventualnom nastavku njihovog školavanja u Italiji. Naime, memorandum se isključivo odnosi na podršku u širenju dvojezičnih srpsko-italijanskih odeljenja u obrazovno-vaspitnim ustanovama u Republici Srbiji. Takođe, sporazum predviđa da italijanska strana preko lektora za italijanski jezik pruža podršku u izvođenju nastave na stranom jeziku, kao i da obezbedi kontinuirano usavršavanje lokalnih nastavnika preko stipendija za pohađanje kurseva i stručne obuke u Italiji.

Jedini formalni dokaz o pohađanju dvojezične nastave izdaje škola. Naime, nakon položenog maturskog ispita škola izdaje diplome u kojima

18 Jelena Gavrović, MA, profesorka italijanskog jezika

19 Memorandum o saradnji između Ministarstva spoljnih poslova Republike Srbije i Ministarstva za spoljne poslove i međunarodnu saradnju Republike Italije u oblasti rada dvojezičnih srpsko-italijanskih odeljenja u Republici Srbiji, 14.03.2017, dostupan na sajtu Treće beogradske gimnazije: http://www.trecagimnazija.edu.rs/memorandum-o-saradnji/ 
se u napomeni navodi da su učenici, ukoliko su tako izabrali, odbranili maturski rad na italijanskom, odnosno francuskom jeziku. Pored ovog zvaničnog dokumenta, po završetku svakog razreda u svedočanstvima navodi se spisak predmeta koji su učenici pratili na stranom jeziku (ovi podaci se nalaze i u Matičnoj knjizi škole) ${ }^{20}$.

\section{Predlozi za model maturskog ispita za strani jezik na kraju srednjoškolskog obrazovanja u dvojezičnoj (CLIL) nastavi na primeru italijanskog jezika u TBG-i}

U skladu sa odlikama i ciljevima CLIL nastave, kao i na osnovu opisanih primera modela maturskog ispita smatramo da bi pojedine elemente iz evropskih iskustava trebalo preneti u obrazovni sistem Republike Srbije i prilagoditi ih lokalnom kontekstu, te tako izmeniti pojedine delove maturskog ispita koji su trenutno zastupljeni u TBG-i.

Naime, mišljenja smo da ispit stranog jezika u dvojezičnoj nastavi treba da bude koncipiran po ugledu na međunarodne sertifikate ${ }^{21}$ sa ciljem testiranja jezičkih kompetencija učenika na nivou B2 prema ZERO-u (prema važećem programu za gimnazije Ministarstva prosvete, nauke i tehnološkog razvoja Republike Srbije ${ }^{22}$ jezički nivo koji poseduju učenici za prvi strani jezik na kraju srednjoškolskog ciklusa odgovara nivou B1+ na produktivnom nivou, odnosno B2 na receptivnom nivou ${ }^{23}$ ). Maturski test za strani jezik bi u skladu sa ciljem testiranja odgovarao tzv. testu postignuća s obzirom da je neophodno proveriti nivo jezičkih kompetencija učenika po završenom srednjoškolskom ciklusu. Stoga, u skladu sa principima sadržaja testa postignuća (Brown, 2004:47), prilikom testiranja osnovnih jezičkih kompetencija (receptivnih i produktivnih) smatramo da

20 Sve relevantne informacije o pravnim odredbama dvojezične nastave u Trećoj beogradskoj gimnaziji dobijene su iz Sekretarijata škole, Katarine Lukić, dipl. pravnice.

21 U skladu sa testovima Univerziteta za strance u Peruđu (tzv. CELI testovi), odnosno Univerziteta za strance u Sijeni (CILS testovi). Primeri testova dostupni su na internet sajtovima za CELI: http://www.cvcl.it/categorie/categoria-104 CILS: http://www.unistrasi.it/1/498/2434/Certificazioni.htm

22 Prosvetni glasnik,Službeni glasnik RS, br. 7, od 27.11.2011. (str. 31-53)

23 Do sada nije izrađen poseban program za strane jezike za dvojezična odeljenja u kojima se strani jezik usvaja u CLIL kontekstu. 
je neophodno usaglasiti sadržaj i tekstualni žanr predmetima koje su učenici pratili u toku nastave na stranom jeziku. Tako na primer, za proveru razumevanja kompetencije čitanja, poželjno je da tekst tematski i sadržinski odgovara jednom od predmeta iz dvojezične nastave, dok bi se za proveru ostalih kompetencija koristili tekstovi vezani za druge nejezičke sadržaje.

U okviru provere metajezičkih kompetencija, potrebno je testirati nivo prepoznavanja i primene jezičkih struktura svojstvenih akademskim kompetencijama koje su učenici razvijali tokom praćenja dvojezične nastave. Pored testiranja gramatičkih struktura ovim zadacima bi istovremeno bila obuhvaćena leksika svojstvena sadržaju predmeta u okviru CLIL nastave.

Kada je reč o strukturi zadataka za testiranje receptivnih i produktivnih jezičkih kompetencija, u skladu sa postavkama komunikativnog pristupa testiranju jezičkih kompetencija i performansi (Brown, 2004:47), preporučljivo je koristiti autentične tekstove sa kontekstualizovanim zadacima. Za proveru jezičke građe, kao i pisanog i usmenog razumevanja neophodno je koristiti didaktičke tehnike koje su korišćene u nastavi, kao što su: pitanja sa višestrukim izborom, close testovi, otvorena i zatvorena pitanja, povezivanje pojmova sa značenjem, odnosno sa odgovarajućim definicijama i slično.

S obzirom da CLIL nastava predstavlja metodu u kojoj strani jezik i predmetni sadržaj imaju podjednaku važnost i stoga podrazumevaju integrisan pristup u nastavi (Coyle et al. 2010: 27), smatramo da je i na maturskom ispitu, kao i u nastavnoj praksi, neophodna međusobna saradnja lokalnog nastavnika koji drži nastavu na stranom jeziku, nastavnika stranog jezika i stranog lektora. S tim u vezi, smatramo da je prilikom izbora stručnih testova za maturski ispit na stranom jeziku neophodno ostvariti pomenutu saradnju nastavnika u cilju adekvtanog izbora teksta, kako u pogledu adekvatnog izbora sadržaja, tako i u pogledu izbora jezičkog nivoa prema ZERO-u.

Iako polaganje maturskog ispita za nejezičke predmete ne predstavlja predmet ovog rada, zbog pomenutih dvojnih ciljeva CLIL nastave nužno smo usmereni i ka ovoj temi. Naime, moguće je primetiti da je opisana praksa u TBG-i koja se odnosi na saradnju nastavnika nejezičkog predmeta, nastavnika stranog jezika i stranog lektora u skladu sa opisanim ciljevima CLIL nastave. Pored očuvanja postojeće saradnje, smatramo da bi bilo neophodno prilagoditi strukturu maturskog ispita ciljevima dvoje- 
zične nastave koja se odnosi na razvoj akademske kompetencije na oba jezika (maternjem i stranom) u skladu sa uslovima koji su neophodni za uspešnu realizaciju dvojezičnog programa kao što ističu autori Krashen i Biber (1988 u Beardsmore, 1993:152). Naime, pomenuti autori izdvajaju tri neophodna uslova za uspešan dvojezičan program: 1) podučavanje nejezičkih predmeta na maternjem jeziku; 2) razvoj veštine čitanja i pisanja na maternjem jeziku; 3) razvoj osnovnih komunikativnih kompetencija na stranom jeziku u okviru nastave stranog jezika, kao i podučavanje nejezičkih predmeta na stranom jeziku koji je prilagođen jezičkom nivou učenika. $\mathrm{S}$ tim u vezi, smatramo da bi bilo uputnije zahtevati od učenika da pisani rad odabranog predmeta za završni ispit sastave samo na maternjem jeziku (a ne na oba jezika kakva je trenutna praksa u TBG-i), dok bi usmenu diskusiju vodili sa komisijom na stranom jeziku, što je u skladu sa najčešće opisanom praksom u Evropi.

Smatramo da je neophodno napomenuti da je izuzetno važna saradnja svih nastavnika koji su uključeni u dvojezičnu nastavu i prilikom ocenjivanja učenika na završnom ispitu, po ugledu na opisani model u Italiji.

Kada je reč o formalnim mogućnostima za svršene učenike dvojezičnih odeljenja, smatramo da je neophodno proširiti postojeći bilateralni sporazum između Republike Italije i Republike Srbije i obezbediti učenicima direktnu prohodnost na italijanske univerzitete kao što je uobičajena praksa u sličnim bilateralnim dogovorima evropskih zemalja (Eurydice,2006: 29).

S obzirom da u zakonskoj regulativi obrazovnog sistema Republike Srbije nije posebno definisana struktura maturskog ispita za dvojezična odeljenja, smatramo da opisani predlozi za model završnog ispita na kraju srednjoškolskog obrazovanja u dvojezičnoj nastavi na primeru italijanskog jezika u TBG-i mogu poslužiti kao smernice za donošenje posebnog pravilnika za ovaj segment CLIL nastave u Srbiji.

\section{Literatura}

Baker, C. (2007). Becoming bilingual through bilingual education. U: Auer, P. \& Wei, L. (prir.) Handbook of Multilingualism and Multilingual Communication. Berlin: Walter de Gruyter

Beardsmore, H. B. (1993). European Models of Bilingual Education. Clevedon, Philadelphia, Adelaide: Multilingual Matters LTD 
Brown, H. D. (2004). Language Assesment: Principles and Classroom Practices. New York: Longman

Coyle, D. Hood,S P. \& Marsh, D. (2010). CLIL. Content and Language Integrated Lerning. Cambridge: Cambridge University Press

Cummins, J. \& Swain, M. (1986) Bilingualism in Education. London: Longman

Danesi, M. (1999) Educazione bilingue: miti e realtà. U: Balboni, P.E. (prir.) Educazione bilingue. (pp. 5-12) Perugia: Guerra Edizioni

Filipović, J. Vučo, J. \& Đurić, Lj. (2007). Critical Review of Language Education Policies in Compulsory Primary and Secondary Education in Serbia. U: Current Issues in Language Planning (str. 222-242), Vol.8, N.1 Channel View Publication

Krashen, S. \& Biber, D. (1988). On Course: Bilingual Education's Successes in California. Sacramento: California Association for Bilingual Education. U: Beardsmore, H. B. (1993). European Models of Bilingual Education. Clevedon, Philadelphia, Adelaide: Multilingual Matters LTD

Tardieu, C. \& Dolitsky, M. (2012). Impact of the CEFR on CLIL Integrating the Task-Based Approach to CLIL teaching. U: Agudo J. d. D. M. (ur.) Teaching and Learning English through Bilingual Education. Cambridge Scholars Publishing

Titone, R. (1972). Bilinguismo precoce ed educazione bilingue. Roma: Armando Vučo, J. (2006). U potrazi za sopstvenim modelom dvojezične nastave. U: Inovacije u nastavi. (XIX, pp. 41-54). Beograd: Učiteljski fakultet

\section{Izvori}

CELI. Međunarodni sertifikati za italijanski jezik kao strani: http://www.cvcl.it/ categorie/categoria-104 [12.01.2018.]

CILS. Međunarodni sertifikati za italijanski jezik kao strani: http://www.unistrasi.it/1/498/2434/Certificazioni.htm [12.01.2018.]

Dekret Ministarstva prosvete Republike Italije o maturskom ispitu br. 429,20.11.2000. god:

http://www.edscuola.it/archivio/norme/decreti/dm2011001.html [10.01.2018.]

Eurydice (2006). Content and Language Integrated Learning (CLIL) at School in Europe. Brussels: European Commission

Evropske škole: https://www.eursc.eu/en/European-Schools/mission [10.01.2018.] Izveštaj aktiva za dvojezičnu nastavu o radu bilingvalnih odeljenja u školskoj 2016/17. Autorke izveštaja: Biljana Mijajlović, rukovodilac aktiva za italijanski jezik i Dragana Pavović, rukovodilac aktiva za francuski jezik (interni školski dokument) 
Mađarsko-engleska gimnazije Tončiš Mihalj (mađ.Táncsics Mihály): http://archive.ecml.at/mtp2/ensemble/results/Kapitanffy.htm [09.01.2018.]

Maturski ispit za srednje škole u Republici Italiji: http://www.istruzione.it/esame di_stato/index.shtml https://www.studenti.it/seconda prova liceo linguistico esame di maturita.html [05.01.2018.]

Memorandum o saradnji između Ministarstva spoljnih poslova Republike Srbije i Ministarstva za spoljne poslove i međunarodnu saradnju Republike Italije u oblasti rada dvojezičnih srpsko-italijanskih odeljenja u Republici Srbiji, 14.03.2017, dostupan na sajtu Treće beogradske gimnazije: http://www. trecagimnazija.edu.rs/memorandum-o-saradnji/ [13.10.2017.]

Ministarstvo prosvete Republike Italije (CLIL obrazovanje): http://www.miur. gov.it/clil [08.01.2018.]

Obrazovni sistem Republike Italije: http://www.miur.gov.it/sistema-educativodi-istruzione-e-formazione [05.01.2018.]

Pravilnik o bližim uslovima za ostvarivanje dvojezične nastave: Službeni glasnik RS“, br. 105/2015, 50/2016.

Pravilniku o ispitima u Trećoj beogradskoj gimnaziji:Pravilnik o ispitima, delovodni broj 01-2808 od 26.12.2013.godine (interni dokument škole)

Program stranih jezika za gimnazije: Prosvetni glasnik,Službeni glasnik RS, br. 7, od 27.11.2011. (str. 31-53).

Propisi za uvođenje CLIL nastave na srednjoškom nivou obrazovanja u Republici Italiji: www.istruzione.it/allegati/2014/Norme Transitorie_CLIL_Licei Istituti Tecnici_Lug2014.pdf [12.01.2018.]

Zakon o srednjem obrazovanju Republike Srbije:http://www.mpn.gov.rs/wpcontent/uploads/2015/08/\%D0\%97\%D0\%B0\%D0\%BA\%D0\%BE\%D0\% BD-\%D0\%BE-\%D1\%81\%D1\%80\%D0\%B5\%D0\%B4\%D1\%9A\%D0\% B5\%D0\%BC-\%D0\%BE\%D0\%B1\%D1\%80\%D0\%B0\%D0\%B7\%D0\%B E\%D0\%B2\%D0\%B0\%D1\%9A\%D1\%83-\%D0\%B8-\%D0\%B2\%D0\%B0 $\% \mathrm{D} 1 \% 81 \% \mathrm{D} 0 \% \mathrm{BF} \% \mathrm{D} 0 \% \mathrm{~B} 8 \% \mathrm{D} 1 \% 82 \% \mathrm{D} 0 \% \mathrm{~B} 0 \% \mathrm{D} 1 \% 9 \mathrm{~A} \% \mathrm{D} 1 \% 83 . \mathrm{pdf}$

[06.01.2018.] 


\section{PROPOSAL OF A MODEL FOR EVALUATION OF FOREIGN LANGUAGE COMPETENCIES IN CLIL WITHIN THE FINAL EXAMINATION IN THE SERBIAN EDUCATION SYSTEM}

Since 2000, the Ministry of Education of Serbia has launched a series of projects in order to modernize Serbian educational system, among which learning of at least two foreign languages during the twelve years of primary and secondary education as well as three or more languages as non-compulsory elective subjects. The introduction of bilingual teaching in L2 and L1 as an innovative approach to learning both linguistic and non-linguistic subjects at primary and secondary level of education falls also into this category (Filipović et al., 2007: 234). Consequently, in 2004, the Third Belgrade High School introduced two bilingual (Italian and French) sections, designed according to CLIL methodology and supported by the Ministry of Education and Sports of the Republic of Serbia for the school year 2004/2005 (Vučo, 2006: 42). Later on, in 2015, the Minister of Education promoted the "Guidelines for the Implementation of Bilingual Education Programmes"which, however, did not completely define all the elements of bilingual teaching in a foreign language.

With that in mind, this paper deals with one of the apparently missing segments in the legal regulations of the Serbian education system that refers to the final exam structure at the secondary education level, with a particular emphasis on foreign language teaching within CLIL (e.g.Italian as a vehicular language).

Therefore, the aim of this paper is to discuss present models of CLIL teaching implemented at the secondary level of education in some European countries. The special focus is on the Italian educational system, as well as on the final exam structure and its specific features, some of which still lack, but should be introduced and developed, in the Serbian education system. A proposal of a possible structure of the Italian language test is also given, hoping that such an instrument could be used as one of the guidelines for evaluation of the foreign language competencies in CLIL as part of the final examination.

Key words: bilingual teaching, foreign language, CLIL method, secondary education, final exam, Third Belgrade High School, Italian-Serbian section, Educational system of the Republic of Serbia 